\title{
Electron-Spin Resonance Study of an Alkaline Solution of Copper(II) Oxalate-meso-Tartrate Complex (The Somogyi Reagent) and Related Complexes
}

\author{
Alexander J. Fatiadi \\ Institute for Materials Research, National Bureau of Standards, Washington, D.C. 20234
}

(February 27, 1970)

\begin{abstract}
Electron-spin resonance (e.s.r.) studies of the structure of four reagents commonly used in the carbohydrate field, namely, the Somogyi reagent, the Fehling reagent, the Benedict reagent, and the Reeves reagent, in frozen aqueous solution at $77 \mathrm{~K}$, gave definite indications of dimer in the Fehling reagent only; the Benedict reagent contains a relatively low concentration of dimer as compared to monomer. The presence of an "extra" peak at 3.245 kgauss in the e.s.r. spectrum of the Somogyi reagent at $25^{\circ} \mathrm{C}$ may be associated with a paramagnetic, superoxide, ion-ligand $\mathrm{O}_{2}^{-}$; at $77 \mathrm{~K}$, extra peaks were observed for the Somogyi, Fehling, and Benedict reagents.
\end{abstract}

Key words: Alkaline; complex; copper, e.s.r.; ligand; paramagnetic; reagent; superoxide; spectra; structure.

\section{Introduction}

Despite considerable work on determination of the structure of coordination complexes $[1-4],{ }^{1}$ there are practically no reports on the structure of the blue complex present in the Somogyi reagent. From early work on determination of the structure of the blue complex present in the related Fehling solution [5], the presence of an ionized species in the complex was indicated, and a five-membered, copper-chelate ring was proposed; the latter was also favored by Cotton and Wilkinson [6].

In an e.s.r. and magnetic-susceptibility study of five copper compounds of D-tartaric acid, Ablov and co-workers [7] proposed a polymeric, chain-type structure for copper D-tartrate trihydrate; however, $\mathrm{x}$-ray analysis of the related vanadyl tartrates showed a binuclear structure [3, 4]. The work of Lefebvre [8] on the composition of copper(II) citrate chelates indicates that they have a monomeric or dimeric structure, depending on $\mathrm{pH}$ and $\mathrm{pCu}$; recent studies on this subject [9-11] have been interpreted as showing the existence, at $\mathrm{pH} 11$ or higher, of a dimer in which two $\mathrm{Cu}^{2+}$ ions are separated by $\sim 0.31 \mathrm{~nm}$.

In general, the e.s.r. spectrum of monomeric species $(\Delta M=1, g \sim 2$ region) in frozen aqueous solution (at $77 \mathrm{~K})$ of $\mathrm{Cu}(\mathrm{II})$ complexes shows a characteristic, single, intense, perpendicular component, $\left(g_{\perp}\right)$ and less-intense, four-line, parallel components $\left(g_{\|}\right)$; the spectrum of the complex can thus be characterized

${ }^{1}$ Figures in brackets indicate the literature references at the end of this paper. by its anisotropic features associated with $g_{\perp}, g_{\|}$and $A_{\perp}, A_{\|}$components [2].

A typical e.s.r. spectrum of the Cu(II) complex in aqueous solution at room temperature shows a fourline, asymmetric pattern due to coupling of an unpaired electron of copper with the nuclear spin of the ${ }^{63} \mathrm{Cu}$ and ${ }^{65} \mathrm{Cu}$ nuclei $\left(I_{\mathrm{Cu}}=\frac{3}{2}\right) ;{ }^{63} \mathrm{Cu}$ and ${ }^{65} \mathrm{Cu}$ have similar nuclear moments [1]. However, e.s.r. spectra of inorganic cupric salts (for example, $\mathrm{CuCl}_{2}, \mathrm{Cu}\left(\mathrm{NO}_{3}\right)_{2}$, or $\mathrm{CuSO}_{4}$ ) in aqueous solution show only a one-line pattern [12] that readily changes to a four-line spectrum on addition of a base (complex formation).

Recent advances, particularly in the application of modern polarography $[9,10]$, conductivity measurements [13], and, especially, low-field e.s.r. spectrometry $[9,11,14,15]$ provide tools for structural studies of coordination complexes. For copper or vanadyl complexes of a dimer having $\Delta M=2$ transitions, an e.s.r. low-field peak is observed $[9,11,14,15]$ at about $\mathrm{H}_{0} / 2$ or $1.6 \mathrm{kG}(g \sim 4)$, whereas a monomer structure $\left(\Delta M=1\right.$ transitions) shows a peak at $g \sim 2\left(\mathrm{H}_{0} / 3.3 \mathrm{kG}\right)$.

\section{Experimental Procedure}

Ultraviolet and visible spectra were recorded with a Beckman DK-2 or Cary 14 spectrophotometer. Electron-spin resonance spectra were recorded with a Varian Model 4500 EPR spectrometer ${ }^{2}$ with $100-\mathrm{kHz}$ field-modulation and detection, operating at $\sim 9.2$

${ }^{2}$ Certain commercial instruments are mentioned in this paper; this does not imply recommendation or endorsement by the National Bureau of Standards. 
and $\sim 9.5 \mathrm{GHz}$. The klystron frequency was measured with a transfer oscillator and frequency counter. The magnetic field was measured by a proton gaussmeter monitored by the same frequency counter. All spectra were recorded in duplicate or triplicate, and the measurements were averaged. Replicate readings for the frequency-counter meter agreed within \pm 3 percent.

The solutions were examined in a Varian Model $\mathrm{V}-4.548$ aqueous-solution sample-cell at various temperatures $\left(25\right.$ to $60^{\circ} \mathrm{C}$ ) and at $77 \mathrm{~K}$. A measured volume of the inosose solution was introduced directly into a cell by means of a microsyringe equipped with a long needle to facilitate mixing. The inosose solution and the reagents were prepared according to the published procedures indicated in the text.

\subsection{Magnetic Parameters $[16,17]^{3}$}

For the e.s.r. calculations, the following equations were employed, where $g_{\text {cal }}$ is the $g$ value calculated from the spectrum, $\nu_{\kappa}=$ klystron frequency, and $\nu_{p}=$ proton frequency; $g_{\text {cal }}=3041.9 \nu_{\kappa} / \nu_{p} ; \Delta$ (gauss) $=\left(\nu_{p}-\nu_{p^{\prime}}\right) \times 2.3486 \times 10^{-4}$. $A$ (in $\left.\mathrm{cm}^{-1}\right)=g_{\text {cal }}-4669$ $\times 10^{-4} \times \Delta$ (in gauss) where there is a separation between peaks. In spectra of liquids (at $25^{\circ} \mathrm{C}$ ), $g_{m}$ is defined as the middle point of the hyperfine lines of the spectrum. For spectra of crystalline materials (at $25^{\circ} \mathrm{C}$ or $77 \mathrm{~K}$ ), identification of $g_{\|}$and $g$, was similar to that in the literature [16, 18]. Calculated $g_{m}$ values for the solution at $25^{\circ} \mathrm{C}$ were in approximate agreement with that calculated by the use of the relationship $g_{m}=\left(2 g_{\perp}+g_{\|}\right) / 3[18]$.

\section{Results and Discussion}

\subsection{Structure of the Alkaline Copper(II) Oxalate- meso-Tartrate Complex (the Somogyi Reagent) and Related Complexes}

Figure 1 shows, for four reagents important in the carbohydrate field, the complete e.s.r. spectra (1.0 to $3.5 \mathrm{kG}$ ) of supercooled $(77 \mathrm{~K})$, polycrystalline samples of the $\mathrm{Cu}$ (II) complexes from aqueous solutions. The reagents studied are: the Somogyi reagent $[\mathrm{A}$, alkaline solution of copper(II) oxalate-meso-tartrate complex $[19,20]]$, the Fehling reagent [B, alkaline copper(II) meso-tartrate complex [21]], the Reeves reagent [C, copper(II) tetraamine hydrate complex [22], and the Benedict reagent $[\mathrm{D}$, alkaline copper(II) citrate complex [21]]. Of these spectra, B and, in part, D (fig. 1) have low-field absorption (1.0-2.0 kG region), suggesting the presence of dimeric as well as monomeric species, whereas A and C lack this feature.

The $\mathrm{Cu}(\mathrm{II})$ complexes present in the Somogyi reagent (in the polycrystalline state at $77 \mathrm{~K}$ and at room temperature) can be envisaged as an equilibrium mixture of meso-tartrate-oxalate monomeric species

${ }^{3}$ See refs. [2] and [17] for a discussion of the magnetic parameters $g_{\|}, g_{\perp}, A_{\|}$, and $A_{\perp}$, and the transitions for metal complexes, $\Delta M=1$ and $\Delta M=2$ for monomer and dimer struc tures, respectively. (a, b, and c), with the following as possible structures for the monomeric anions: ${ }^{4}$

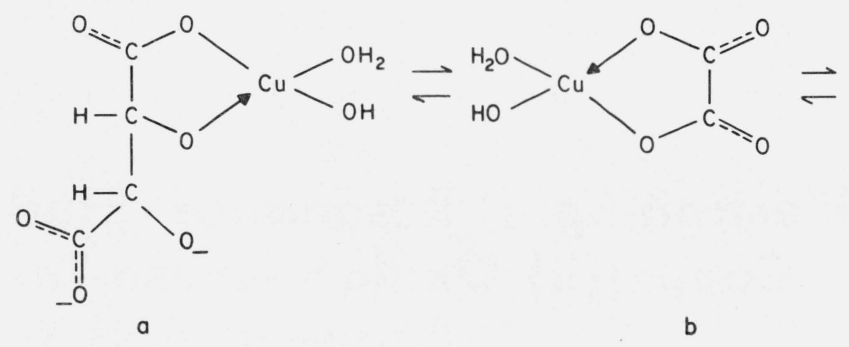<smiles>O=C1O[C@]2(C(=O)O)OC(=O)[C@@H]1O2</smiles>

FORMULA I

Evidence is now presented, for the first time, ${ }^{5}$ for the existence of a dimer of the $\mathrm{Cu}(\mathrm{II})$ tartrate complex of the Fehling reagent at $77 \mathrm{~K}$; a polynuclear, complex structure for this reagent had been suggested without proof $[22,23]$. The low-field lines $(1.6 \mathrm{kG})$ of the e.s.r. spectrum of the frozen Fehling solution ( $\mathrm{B}$, fig. 1) may be associated with the $\Delta M=2$ transitions $^{6}$ of a $\mathrm{Cu}^{2+}-\mathrm{Cu}^{2+}$ ion pair, as has been suggested for other complexes [14, 17]. Hence, the evidence strongly suggests the existence of a dimer in the Fehling solution at $77 \mathrm{~K}$. A possible structure for a dimer present in the Fehling reagent is depicted, where $a^{\prime}$ and $c^{\prime}$ are meso-tartrate hydroxyl-carboxylate ligands that bridge [25] the $\mathrm{Cu}^{2+}(\mathrm{OH})^{-}-\mathrm{Cu}^{2+}(\mathrm{OH})^{-}$ion-pair $b^{\prime}$ to give five-membered, chelate rings (a strongly alkaline reagent facilitates the ionization of the hydroxyl groups of meso-tartaric acid). The e.s.r. spectrum of the Fehling reagent at room temperature did not show the low-field absorption as observed elsewhere for $\mathrm{Cu}(\mathrm{II})$ sulfosalicyclic acid dimer [11].

The e.s.r. spectrum of the Benedict reagent at $77 \mathrm{~K}$ (spectrum D, fig. 2) shows much broader, weaker, low-field absorption at 1.5 to $2.0 \mathrm{kG}$; it may also indicate the presence of a dimer. Indications of dimer in $\mathrm{Cu}(\mathrm{II})$ citrate complex at different $\mathrm{pH}$ 's have been found $[9,11]$. This sort of existence of dimers is lacking in the Somogyi reagent $(\mathrm{A})$ and the Reeves reagent $(\mathrm{C}) .^{7}$

\footnotetext{
${ }^{4}$ The coordination number of $\mathrm{Cu}(\mathrm{II})$ complexes in solution is larger than that of such complexes in the solid state; consequently, an aqueous Cu(II) meso-tartrate-oxalate complex may contain two water ligands that provide a maximum coordination number of six. After completion of this work, Chasteen, N. D. and Belford, R. L., [J. Inorg. Chem., 9, 169 (1970)] described the e.s.r. spectra of alkaline Cn(II) D, DL, and meso-tartrates; the authors found a binuclear copper complex with the racemic or DL-tartrate only. The Fehling reagent used in this study was prepared from a commercial Rochelle salt, a mixture of potassium-sodium-meso and D-tartrates.

${ }_{6}^{6}$ Reference [24] describes application of high-field e.s.r. spectrometry $\left(\mathrm{H}_{0} 3.6-4.0 \mathrm{kG}\right)$ to a study of transitions $\Delta M=2$; the paper discusses a dimer structure for $\mathrm{Cu}$ (II) propionate monohydrate, for which a seven-line spectrum was observed.

The Reeves reagent has proved to be a useful tool in conformational analysis [26, 27]; see also, refs. [28, 29], describing other possible structures for $\mathrm{Cu}(\mathrm{II})$-tetraamine complexes $\left[\mathrm{Cu}\left(\mathrm{NH}_{3}\right)_{4} \cdot\left(\mathrm{H}_{2} \mathrm{O}\right)_{2}\right]^{2+}$
} 


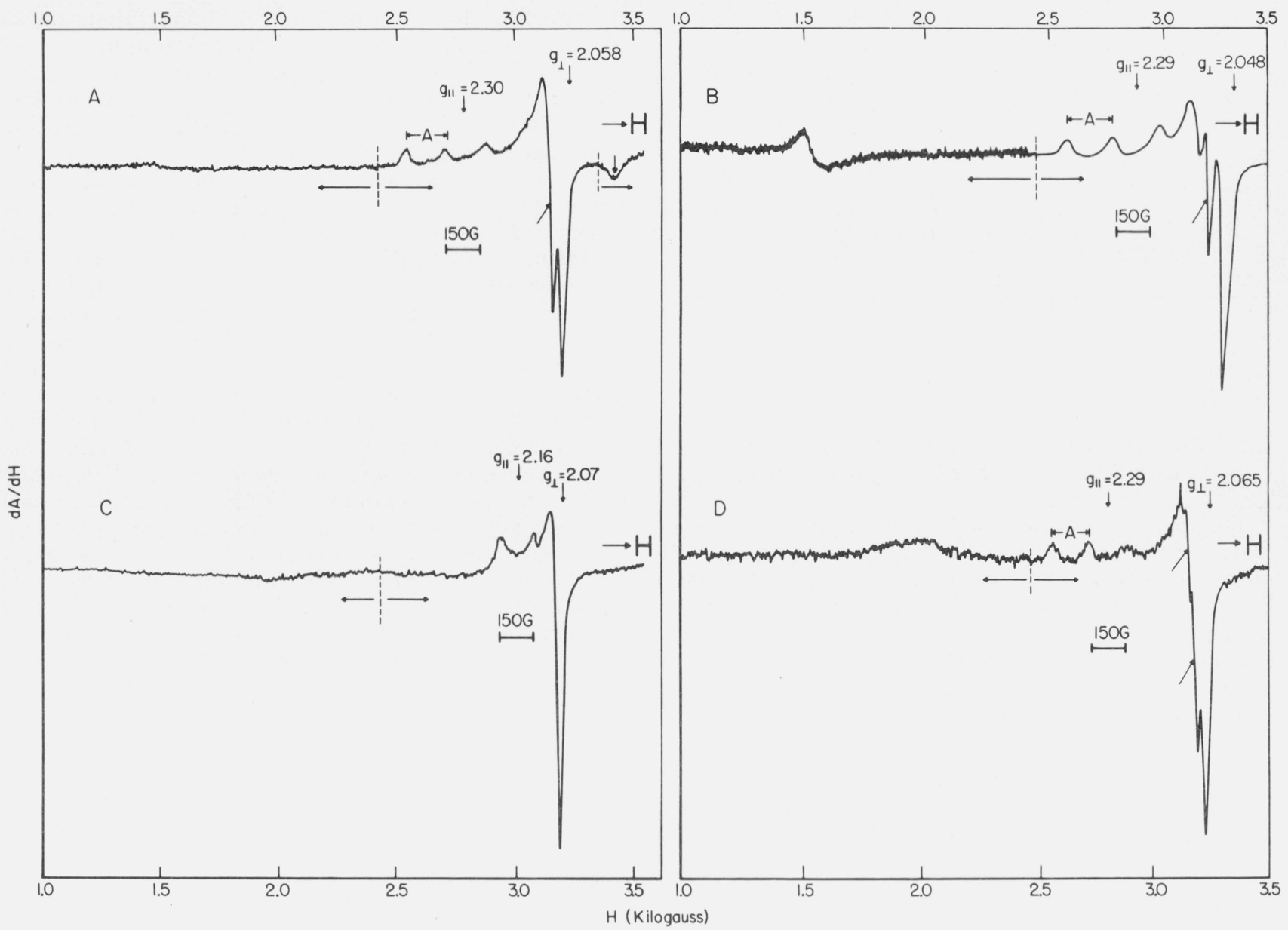

FIGURE 1. E.s.r. spectra of frozen $(77 \mathrm{~K})$ aqueous alkaline solutions of $\mathrm{Cu}(\mathrm{II})$ complexes: spectrum $A$, meso-tartrate-oxalate (the Somogyi reagent); $B$, meso-tartrate (the Fehling reagent); $C$, citrate (the Benedict reagent); and D, tetraamine hydrate (cuprammonium, the Reeves reagent). All four low-field e.s.r. spectra on the left side of the dotted line were recorded at somewhat greater field-modulation amplitude than the spectra for the $g \sim 2$ region. A signal at $3.46 k G$ (spectrum A) was obtained at the same fieldmodulation amplitude as that used for the low-field spectrum.

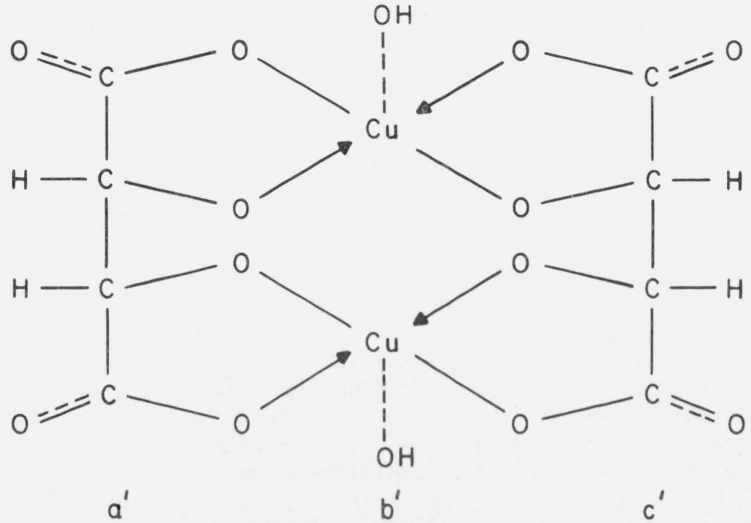

FORMULA 2
The hyperfine structure in the e.s.r. spectrum of the freshly prepared Benedict reagent at room temperature slowly disappears as the reagent ages, although the oxidizing power remains. For example, a three-year-old reagent showed only a one-line e.s.r. spectrum having width $\Delta=19.3$ gauss and $g_{m}=2.091$; the associated structural changes remain unexplained.

Some overlap is observed in all four of the e.s.r. spectra of figure 1. Spectrum C is highly atypical and does not show the four components. The magnetic parameters for the monomeric species are given in table 1; the table also shows the coupling constants $\left(a_{\mathrm{Cu}}\right)$ found for the $\mathrm{Cu}(\mathrm{II})$ complexes of the four reagents in solution (at room temperature). 
TABLE 1. Magnetic parameters a for the $C u(I I)$ complexes of the Somogyi $(A)$, Fehling $(B)$, Reeves $(C)$, and Benedict $(D)$ Reagents at $77 \mathrm{~K}$, and the coupling constants $\mathrm{a}_{\mathrm{Cu}}$ for the reagents at $25^{\circ} \mathrm{C}$

\begin{tabular}{|c|c|c|c|c|}
\hline Reagent & $g_{\perp}$ & $g_{\|}$ & $\begin{array}{c}A_{\|} \\
\left(\mathrm{cm}^{-1} \times 10^{-4}\right)\end{array}$ & $\begin{array}{c}a_{\mathrm{Cu}} \\
\text { (gauss) }\end{array}$ \\
\hline A & $2.058 \pm 0.003$ & $2.302 \pm 0.005$ & $164 \pm 10$ & \multirow{4}{*}{$\begin{array}{l}{ }^{\mathrm{b}} 67 \pm 1 \\
\mathrm{c} \\
68 \pm \\
\mathrm{d} \\
\mathrm{e} 80 \pm \\
\mathrm{e}_{47 \pm}\end{array}$} \\
\hline B & $2.048 \pm 0.004$ & $2.294 \pm 0.003$ & $188 \pm 10$ & \\
\hline C & $2.072 \pm 0.001$ & & & \\
\hline $\mathrm{D}$ & $2.065 \pm 0.003$ & $2.291 \pm 0.002$ & $165 \pm 5$ & \\
\hline
\end{tabular}

${ }^{\text {a }}$ Indicated limits of error for the $g, A$, and $a_{\mathrm{Cu}}$ values are based on repeatability of meas urements of reference points in the spectra.

b For spectrum E, figure 3 .

c For spectrum Y, figure 2 .

d For spectrum $\mathrm{A}-1$, figure 2 .

e For spectrum B-1, figure 2 .

\subsection{The Nature of Complexing Ligands (meso-Tartrate and Oxalate) in the Somogyi Reagent}

The results of a recent kinetic study [30] indicate that, in order to achieve stability in solution for complexes of $\mathrm{Cu}(\mathrm{II})$, it is necessary to have at least a bidentate donor coordinated to the metal ion. In the Somogyi reagent, the bidentate ligands are the organic anions oxalate and meso-tartrate; the former, because of its structure, provides a continuous pathway between the metal ions of conjugated $\pi$ bonds that allows electron exchange to occur about a hundred times faster than do the others [31]. However, as will be shown, the complexing power (ability) of the oxalate anion present in the Somogyi reagent is far below that of the meso-tartrate anion present.

In order to obtain more information about the monomer relationship of the oxalate and meso-tartrate ligands present in the Somogyi reagent, the e.s.r. spectrum of an aqueous solution of each at room temperature was separately studied. It was found that, when potassium-sodium meso-tartrate was omitted from the reagent (all other constituents unchanged), a blue solution was obtained having the prominent e.s.r. spectrum depicted in T, figure 2; however, soon after preparation of the solution, crystallization of a bluish white copper oxalate complex started, and this proceeded continuously for several days. The shape of the e.s.r. spectrum of the solid (E-1, fig. 2) suggests a magnetically dilute sample that could have a polycrystalline structure. The solid decomposes on recrystallization from water, but is stable when recrystallized from basic solution. It was also observed that addition of reagent containing potassium-sodium meso-tartrate (U, fig. 2) to the oxalate solution keeps the copper oxalate complex in solution. This result indicates that,
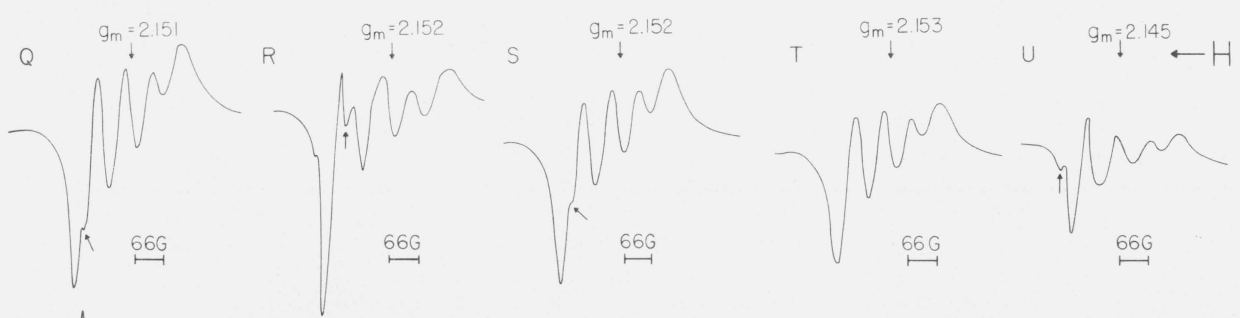
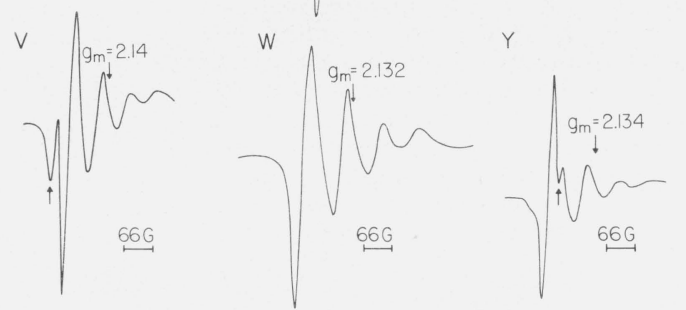

Z

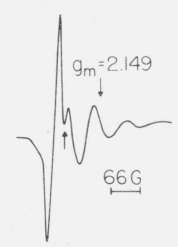

$A-1$
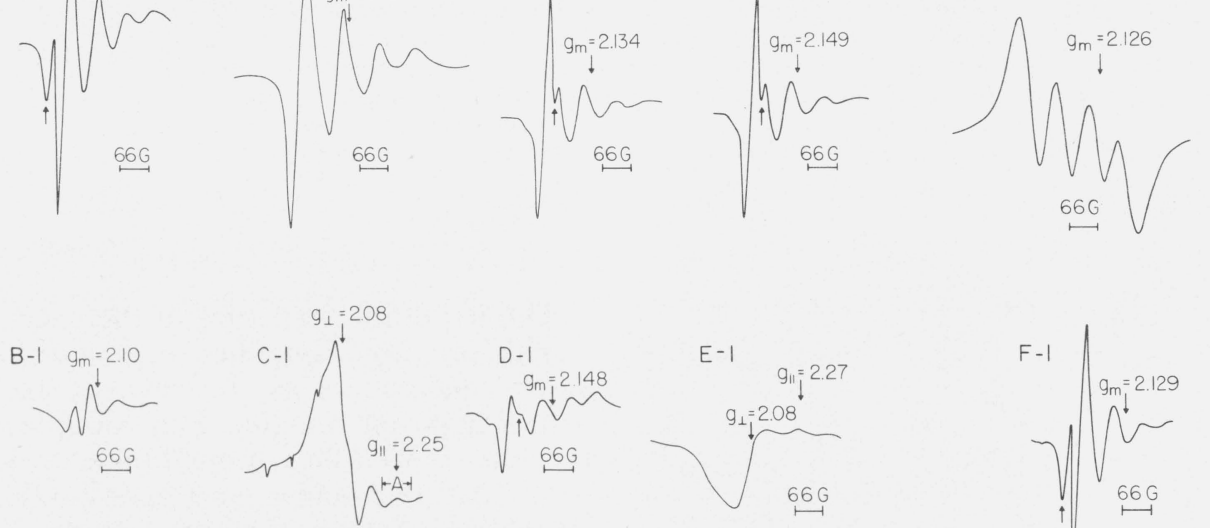

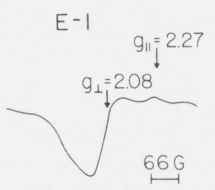

$66 \mathrm{G}$

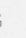

Figure 2. E.s.r. spectra of selected $\mathrm{Cu}(\mathrm{II})$ complexes at $25^{\circ} \mathrm{C}$ : spectrum $Q$, the Somogyi reagent in which copper sulfate was added as the last constituent; $R$, the Somogyi reagent containing ${ }^{65} \mathrm{Cu}$ isotope; $S$, the Somogyi reagent containing ${ }^{63} \mathrm{Cu}$ isotope; $T$, the Somogyi reagent containing oxalate ligand only; $U$, the Somogyi reagent containing tartrate ligand only; $V$, the Fehling reagent in $\sim 200 \mathrm{mM}$ sodium carbonate; W, the Fehling reagent in $\sim 50 \mathrm{mM}$ sodium hydroxide; Y, freshly prepared Fehling reagent; $Z$, the Somogyi reagent in deuterium oxide; $A-1$, the Reeves reagent; $B-1$, the Benedict reagent; $C-1$, the freeze-dried solid from the Somogyi reagent; $D-1$, solid $G-1$ dissolved in deoxygenated water; $E-1$, the solid from the oxalate solution $T ; F-1$, the Fehling reagent in deuterium oxide. 
in the Somogyi solution, the $\mathrm{Cu}(\mathrm{II})$ oxalate complex cannot long exist in solution in the absence of a more powerful complexing agent, namely, the meso-tartrate anion, but that the latter (alone) can exist. The $\mathrm{Cu}(\mathrm{II})$ meso-tartrate complex (U, fig. 2) has about one tenth the derivative peak-height of the $\mathrm{Cu}$ (II) oxalate complex (T, fig. 3). The e.s.r. spectrum of the Somogyi reagent prepared in deuterium oxide ( $Z$, fig. 2$)$ was difficult to reproduce. Sometimes, it was similar to that for the aqueous solution (for example, spectrum $R$, fig. 2), and sometimes it was identical with that of the Fehling reagent prepared in deuterium oxide $(\mathrm{F}-1$, fig. 2).

\subsection{The Nature of the Extra Lines Observed in the E.S.R. Spectra of the Somogyi and Related Reagents}

Various workers $[9,32]$ have observed the presence of extra lines, in addition to four transitions, in a variety of $\mathrm{Cu}(\mathrm{II})$ complexes. Recently, Baines and coworkers [33] observed a multilined e.s.r. spectrum for $\mathrm{Cu}(\mathrm{II})$ complexes in frozen sodium hydroxide and in a frozen sodium hydroxide-cellulose system. The authors [33] explained the extra paramagnetic species observed as being due to trapped electrons that subsequently formed radicals; however, these are very reactive species that could not be observed at room temperature [34-43].

The e.s.r. spectrum of the Somogyi reagent at room temperature (E, fig. 2) shows an extra line at about $3.245 \mathrm{kG}(g=2.068$, indicated by the arrow, E) and this signal slowly increased in magnitude with the "aging", of the reagent caused by exposure to daylight. On freezing, the extra line seems to shift reversibly toward the $g_{\perp}$ line $(g=2.072$; see arrow in A, fig. 1).

A similar reversible shift on cooling was also observed for the Fehling reagent; the extra line observed at $77 \mathrm{~K}$ (indicated by the arrow in B, fig. 1) shifted on warming the sample to room temperature (Y, fig. 2), and this spectrum was identical with that of freshly prepared Fehling reagent. The similarity between spectra $\mathbf{E}$ (fig. 3) and Y (fig. 2) is also evident.

Examination of the e.s.r. spectrum Q may lead.to confusion regarding the extra line for the ${ }^{63} \mathrm{Cu}$ isotope, as a slight difference in the nuclear spins of ${ }^{63} \mathrm{Cu}$ and ${ }^{65} \mathrm{Cu}$ isotopes has been deduced from spectra by the use of Kivelson's method [44, 45]. To eliminate this remote possibility of confusion regarding the extra line for the ${ }^{63} \mathrm{Cu}$ isotope, separate Somogyi reagents containing ${ }^{65} \mathrm{Cu}$ and ${ }^{63} \mathrm{Cu}$ isotopes, respectively, were prepared, and their e.s.r. spectra were examined (spectra $\mathrm{R}$ and $\mathrm{S}$ in fig. 2 for ${ }^{65} \mathrm{Cu}$ and ${ }^{63} \mathrm{Cu}$, respectively). From the position of their strongest peaks (at about $3.277 \mathrm{kG}$ for ${ }^{63} \mathrm{Cu}$, and $3.270 \mathrm{kG}$ for ${ }^{65} \mathrm{Cu}$, as compared to $3.275 \mathrm{kG}$ for the Somogyi reagent prepared from the natural-abundance mixture of ${ }^{65} \mathrm{Cu}$ and ${ }^{63} \mathrm{Cu}$ ), it was concluded that the extra peak in spectrum $\mathrm{Q}$ does not arise from ${ }^{63} \mathrm{Cu}$, which would be difficult to observe under ordinary conditions $[1,44]$. The extra peak was also observed in the spectrum of the Somogyi reagent prepared from the ${ }^{65} \mathrm{Cu}$ and ${ }^{63} \mathrm{Cu}$ isotopes, respectively, and measured at $77 \mathrm{~K}$.
Study of the extra lines observed in the e.s.r. spectra of the Somogyi and related reagents at room temperature was approached from several different angles. The possibility that the extra line in the e.s.r. spectrum of the Somogyi reagent arises from a labile, paramagnetic ligand of the $\mathrm{Cu}(\mathrm{II})$ complex received support from several pertinent observations: (1) the position and intensity of the extra line was found to be $\mathrm{pH}$-dependent (see fig. 3); (2) the line decreased in size, and finally disappeared, on successive treatment with a reducing compound, namely, inosose (fig. 4, see arrows); and (3) it was lessened in size by bubbling nitrogen through the solution or by using deoxygenated water to prepare the reagent (see spectra C-1 and D-1, fig. 2). Moreover, as already mentioned, this extra line had a tendency to (a) increase in intensity and shift to higher field on "aging" by exposure to daylight or by slight warming, (b) decrease in intensity when kept in the dark, and (c) be somewhat dependent on the order of mixing of the components.

The possibility that the extra line was due to impurity in the reagents was eliminated. A typical e.s.r. spectrum of the Somogyi reagent ( $\mathrm{E}$, fig. 3 ) showed an extra line at about $3.245 \mathrm{kG}$ (see arrow). This reagent was successively titrated with an aqueous base (50 to $200 \mathrm{~m} M$ sodium hydroxide), and the change in the shape of the e.s.r. spectrum was monitored. Spectrum $\mathrm{G}$ (fig. 3) was obtained at about $\mathrm{pH} 10.1$ (range 9.6 to 10.3); it showed a decrease in intensity of the extra peak (see arrow); at $\mathrm{pH} 10.9$ (range 10.6 to 11.0 ), the peak appeared as a shoulder (spectrum I, arrow); at $\mathrm{pH} 11.5$ (range 11.2 to 12.1 ), it shifted to higher field (K, arrow). A further addition of base, to $\mathrm{pH} 13.2$ (range 13.0 to 14.0 ), produced an increase in intensity of the peak (F, arrow), and, at $100 \mathrm{~m} M$ in base, the extra line reached the maximum intensity $(\mathrm{H}$, arrow), resembling the spectrum of the Somogyi reagent containing $\mathrm{Cu}(\mathrm{II})$ tartrate only (U, fig. 2).

Also, treatment of the Somogyi reagent with aqueous acetic acid ( $1 M)$ caused shift of the original extra line. At $\mathrm{pH} 8.8$ (range 8.3 to 8.9 ), the line appeared as a shoulder at the strongest peak (J, fig. 3, arrow), and, at pH 7.6 (range 7.5 to 7.8 ), it disappeared completely and irreversibly, to give a four-line, asymmetric, e.s.r. pattern (L, fig. 3) typical of $\mathrm{Cu}(\mathrm{II})$ complex [1]. This spectrum resembles that of the Somogyi reagent containing, as the organic ligand, oxalate only (T, fig. 2); further addition of acetic acid to the probe caused liberation of iodine that interfered with the measurements. However, when the Somogyi reagent, prepared without potassium iodide or iodate, was neutralized to about pH 6 (1 $M$ hydrochloric acid), the e.s.r. spectrum obtained showed a one-line pattern, similar to that for neutral cupric salts [12].

The results of the foregoing experiments detinitely prove the lability and $\mathrm{pH}$-dependence of the "extra" paramagnetic species present in the Somogyi reagent; they also indicate the basic character of the species that could not exist below $\mathrm{pH}$ 8.0. As judged from the shape of the e.s.r. spectra $(\mathrm{H}, \mathrm{L}$, fig. 3 , and $\mathrm{T}, \mathrm{U}$, 


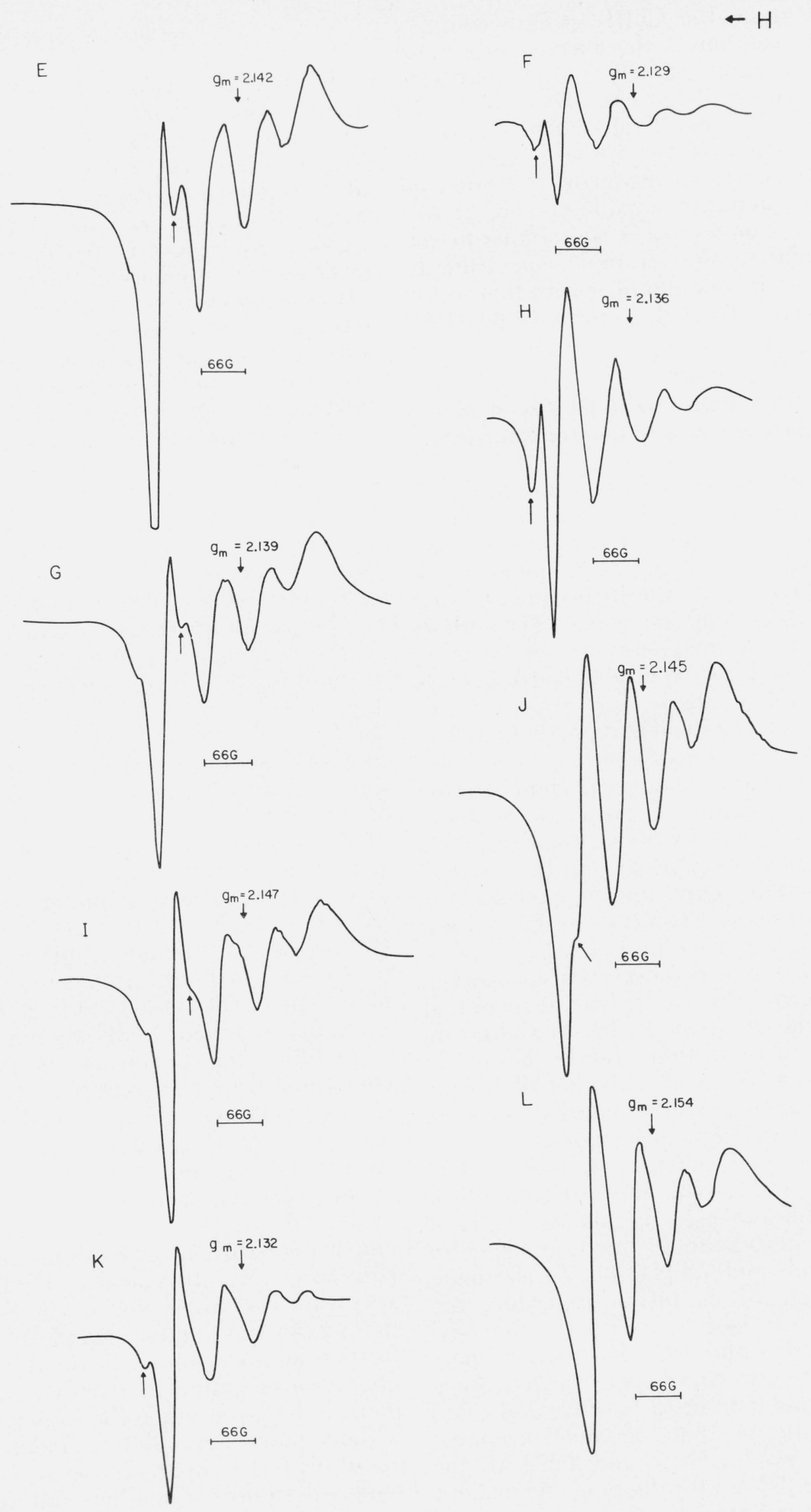

FiguRe 3. E.s.r. spectra of the Somogyi reagent at $25^{\circ} \mathrm{C}$, at various $p H$ 's: $E, p H$ 9.4; $\mathrm{G} \sim 10.1$ (range 9.6 to 10.3$) ; \mathrm{I} \sim 10.9$ (range 10.6 to 11.00$) ; \mathrm{K}, \sim 11.5$ (range 11.2 $\mathrm{G}, \sim 10.1$ (range 9.6 to 10.3 , $\sim \mathrm{H} \sim 100 \mathrm{mM}$ sodium hydroxide; $\mathrm{J}, \mathrm{pH}$ to 12.1 ); F, $\sim 7.3$ to 8.9 ); and $L, \sim 7.6$ (range 7.5 to 7.8 ). 
species that could possibly arise in the alkaline Somogyi reagent is shown in the following reactions:

$$
\begin{gathered}
\mathrm{OH}^{-}+\mathrm{O}_{2} \stackrel{\text { catalyst }}{\longrightarrow} \cdot \mathrm{OH}+\dot{\mathrm{O}}_{2}^{-} \\
\mathrm{OH}^{-}+\dot{\mathrm{O}}_{2}^{-} \longrightarrow \mathrm{OH}^{-} \mathrm{O}_{2}^{2-} \\
2 \cdot \mathrm{OH} \longrightarrow \mathrm{H}_{2} \mathrm{O}_{2}
\end{gathered}
$$

The energy required for the first two reaction-sequences to occur can be supplied by photons [51], or another species equivalent to paramagnetic $\mathrm{O}_{2}^{-}$can be formed by the reaction of a semidone radical ( $R^{\prime}$, see below) with $\mathrm{O}_{2} ; \mathrm{R}^{\prime}+\mathrm{O}_{2} \rightarrow \mathrm{R}^{\prime} \mathrm{O}_{2}$. The catalyst that could possibly initiate this reaction sequence could be $\mathrm{Cu}^{2+}$ ion, photon [51] (colored Somogyi solution, 690-700 nm) with the possible excitation of $d$ electrons $[52],{ }^{9}$ an indirect influence of the hydrated electron [43], or a trace proportion of the semidone type of radical derived from meso-tartaric acid or any hydroxy carboxylic acid. The paramagnetic products would then be stabilized in equilibrium, in an anion vacancy $\left(\mathrm{OH}^{-}\right.$ ligands), after all transitory species (such as $\cdot \mathrm{OH}$ radicals) had been decomposed.

Calculation of the $g$ values possible arising from the paramagnetic superoxide ions $\left(\dot{\mathrm{O}}_{2}^{-}\right)$observed in the frozen solutions at $77 \mathrm{~K}$ (see fig. 1) gave the following values: for the Somogyi reagent (A, arrow next to $g_{\perp}$ line), $g=2.072$, and the presence of another, unknown, extra line at $3.459 \mathrm{kG}$ with $g=1.912$ (A, arrow far right) was observed; for the Fehling reagent, $g=2.054$ (B, indicated by the arrow); and for the Benedict reagent, $g=2.068$ and $g=2.074$ (D, arrows). These values are roughly comparable to the assigned $g$ values of mononegatively charged oxygen ions, $g\left(\mathrm{O}^{-}\right)=2.06$, obtained $[39,40]$ on radiolysis of strongly alkaline ices at $77 \mathrm{~K}$, or $g\left(\mathrm{O}_{2}^{-}\right)=2.089$ at $77 \mathrm{~K}$ [Ref. 40 , p. 156].

Taking into consideration the chemistry and the catalytic ability of $\mathrm{Cu}$ (II) in oxidation-reduction reactions involving molecular oxygen in enzymic $[54,55]$ and nonenzymic systems [56-58], or in ligand-transfer [59] or electron-transfer [60] oxidations, the idea that $\mathrm{Cu}(\mathrm{II})$ complex may contain active oxygen, either as an addition, $\pi$-electron-bonded, ethylene type of complex $[49,61,62]$

$\underset{\mathrm{O}}{\ddot{\mathrm{O}}=\mathrm{O}}$ or as an anion ligand $\ddot{\mathrm{O}}_{+}=\underset{\mathrm{Cu}(\mathrm{II})}{\mid}$

In the first example, in the $\mathrm{CuO}_{2}-\mathrm{Cu}(\pi$-electronbonded complex), the molecule will be diamagnetic, the spins being completely coupled in the metalmetal bond $[49,61,62,63]$. Analogous oxygen-containing complexes have been reported for a series of transition metals, such as iridium [63-65], platinum [66], cobalt [63, 67, 68], and others [69].

\footnotetext{
${ }^{9}$ In analogy to electron transfer with an ion pair [52] $\left(\mathrm{Fe}^{3+} \mathrm{OH}^{-} h \nu \mathrm{Fe}^{2+}+\cdot \mathrm{OH}\right)$, the following reaction is also feasible [53]: $\mathrm{Cu}^{2+} \mathrm{OH}_{-}^{-} h \nu \mathrm{Cu}^{2+}+\cdot \mathrm{OH}$.
}

In the second case, in which the active oxygen in the $(\mathrm{Cu}(\mathrm{II}))$ complex is present as an anion $\left(\dot{\mathrm{O}}_{2}^{-}\right)$, for example in $\left(\mathrm{CuO}_{2}\right)^{2+}$ or in $\left(\mathrm{CuO}_{2} \mathrm{Cu}\right)^{2+}$ cations, the spin in the oxygen anion remains uncoupled, and, in the e.s.r. spectrum, these complexes would be expected to give one extra line, in addition to four others. The existence of such peroxo or superoxo complexes has been proposed for certain phenolases [70-72] and for certain metallo-proteins, such as hemoglobin, that was able to carry molecular oxygen $[63,73]$, or combine with it in certain electron-transfer processes, for example, in the two-step transfer mechanism proposed for oxidase, laccase, and other enzymes [74].

For example, beginning with a diamagnetic $\mathrm{Cu}(\mathrm{II})-$ oxygen adduct $c$ ( $\pi$-complex), an electron transfer in an alkaline solution may involve an oxygen bridge; as a result, an ionic superoxo complex $d$ containing a paramagnetic ligand $\dot{\mathrm{O}}_{2}^{-}$(or a peroxo nonparamagnetic ligand $\mathrm{O}_{2}^{2-}$ ) could be formed. This transfer can be visualized as follows:

$$
\begin{array}{cc}
\mathrm{Cu}(\mathrm{II})-\mathrm{O}_{2}(\uparrow \downarrow)-\mathrm{Cu}(\mathrm{II}) \leftrightarrow \mathrm{Cu}(\mathrm{II})(\downarrow)-\dot{\mathrm{O}}_{2}^{-}(\uparrow)-\mathrm{Cu}(\mathrm{I}) \\
c & \mathrm{Cu}(\mathrm{II})(\downarrow)-\mathrm{O}_{2}^{2-}-\mathrm{Cu}(\mathrm{II})(\uparrow) \\
\pi \text {-complex } & d
\end{array}
$$

\section{ionic superoxo complex.}

In addition to these adducts containing either molecular oxygen or an superoxo type of group, and the old oxidants manganese dioxide and lead dioxide, there have recently been discovered germainum peroxide [75], the specific oxidant nickel peroxide [76-78], the perferryl cation $\mathrm{FeO}_{2}^{2+},[79]$ and the $\mathrm{Cu}^{2+}$-hydrogen peroxide complex $\left(\mathrm{CuO}_{2} \mathrm{H}^{+}\right)$[80].

All of the evidence presented here indicates the existence of the superoxo type of ligand in the $\mathrm{Cu}(\mathrm{II})$ complex in both the Somogyi and the Fehling reagent at room temperature and in the polycrystalline state at $77 \mathrm{~K}$. However, the possibility is not excluded that a certain proportion of the extra lines observed in the e.s.r. spectra of the Somogyi reagent, the Fehling reagent, and, particularly, the Benedict reagent (see arrows, fig. 1) at $77 \mathrm{~K}$ may be due to the perpendicular features from ${ }^{63} \mathrm{Cu}$ and ${ }^{65} \mathrm{Cu}$ isotopes modified by quadrupole interaction, but their separation may be obscured by overlap with features derived from the superoxide ion.

I thank colleagues at NBS: T. Murphy for samples of ${ }^{63} \mathrm{Cu}$ and ${ }^{65} \mathrm{Cu}$ salts, N. Adams for the e.s.r. measurements, R. E. Florin for a useful discussion, R. S. Tipson for his encouragement, and R. Schaffer for his support.

\section{References}

[1] Lewis, W. B., and Morgan, L. O., in Transition Metal Chemistry, 4, 82-90, R. L. Carlin, Ed. (M. Bekker, New York, 1968),

[2] Kokoszka, G. F., and Gordon, G., in Technique of Inorganic Chemistry, 7, 188-198, H. B. Jonassen and A. Weissberger, Eds. (Interscience Publishers, New York, 1968). 
[3] Forrest, J. G., and Prout, C. K., J. Chem. Soc, (A) (1967) 1312.

[4] Chasteen, N. D., Belford, R. L., and Paul, I. C., Inorg. Chem. 8, 408 (1969).

[5] Sidgwich, N. V., The Chemical Elements and Their Compounds, pp. 168-170 (Oxford Univ. Press, Oxford, England, 1951).

[6] Cotton, F. A., and Wilkinson, G., Advanced Inorganic Chemistry, p. 157 (Interscience Publishers, 2nd edition, 1966).

[7] Ablov, A. V., Popovich, G. A., and Suntsov, E. V., J. Structur. Chem. 9,861 (1968).

[8] Lefebvre, J., J. Chem. Phys. 54, 581 (1957).

[9] Dunhill, R. H., Pilbrow, J. R., and Smith, T. D., J. Chem. Phys. 45, 1474 (1966).

[10] Rajan, K. S., and Martell, A. E., J. Inorg. Nucl. Chem. 29, 463 (1967).

[11] Boss, J. F., Dunhill, R. H., Pilbrow, J. R., Strivastave, R. C., and Smith, T. D., J. Chem. Soc. (A) (1969) 94

[12] Fujuwara, S. and Hayashi, H., J. Chem. Phys. 43, 23 (1965).

[13] Howe, A., and Fensham, P. J., Quart. Rev. 2 1, 507 (1967).

[14] Belford, R. L., Chasteen, N. D., So, H., and Tapscott, R. E., J. Amer. Chem. Soc. 91, 4675 (1969).

[15] Hitchman, M. A., and Belford, R. L., in T. F. Yen, Editors, Electron Spin Resonance Spectrum of Metal Complexes (Plenum Publishing Co., New York, N.Y., 1969, chapter 7).

[16] Carrington, A., and McLachlan, A. D., Introduction to Magnetic Resonance, pp. xix, 4, 72, 99. 132, and 157 (Harper and Row, New York, 1967).

[17] Atkins, P. W., and Symons, M. C. R., The Structure of Inorganic Radicals (Elsevier Publishing Co., New York, 1967, chapter 5).

[18] McCarvey, B. R., J. Phys. Chem. 60,71 (1956).

[19] Somogyi, M., J. Biol. Chem. 70, 599.

[20] Schaffer, P. A., and Somogyi, M., J. Biol. Chem. 100,695 (1933).

[21] Shriner, R. L., Fuson, R. C., and Curtin, D. Y., The Systematic Identification of Organic Compounds, 4th Edition, pp. 102-103 (John Wiley \& Sons, New York, 1956).

[22] Ref. [6], pp. 905-907.

[23] Dunlop, J. H., Evans, D. F., Gilland, R. D., and Wilkinson, G., J. Chem. Soc. (A) (1966) 1260.

[24] Kokoszka, G. F., Linzer, M., and Gordon, G., Inorg. Chem. 7, 1730 (1968).

[25] Rossotti, F. J. C., in Modern Coordination Chemistry, Principles and Methods, p. 68, J. Lewis and R. G. Wilkins, Eds. (Interscience Publishers, New York, 1960).

[26] Bukhari, S. T. K., Guthrie, R. D., Scott, A. I., and Wrixon, A. D., Chem. Commun. 1968, 1580.

[27] Bukhari, S. T. K., Guthrie, R. D., Scott, A. I., and Wrixon, A. D., J. Chem. Soc. (C) 1969, 1073.

[28] Gustafson, R., and Martell, A., J. Amer. Chem. Soc. 81, 525 (1959).

[29] Countney, R., Gustafson, R., Chaberek, S., and Martell, A., J. Amer. Chem. Soc. 81, 519 (1959).

[30] Martell, A. E., in Reactions of Coordinated Ligands and Homogeneous Catalysis, D. H. Busch, Ed. (Amer. Chem. Soc. Monograph, Washington, D.C., 1963, p. 161).

[31] Ref. 6, p. 181.

[32] Gershmann, H. R., and Swalen, J. D., J. Chem. Phys. 36, 3221 (1962).

[33] Bains, M. S., Hinojosa, O., and Arthur Jr., J. C., Carbohyd. Res. 6, 233 (1968).

[34] Walker, D. C., Quart. Rev. 21, 79 (1967).

[35] Anbar, M., Quart. Rev. 22, 578 (1968).

[36] Rich, R., Periodic Correlations, p. 110 (W. A. Benjamin, Inc., New York, 1965).

[37] Hart, E. J., Accounts Chem. Res. 2, 161 (1969).

[38] Blandamer, M. L., Shields, L., and Symons, M. C. R., Nature 199, 902 (1963).

[39] Schulte-Frohlinde, D., and Eiber, K., Z. Naturforsch., 1 7a, 445 (1962); 18a, 199 (1963).

[40] Ayscough, P. B., Electron Spin Resonance in Chemistry, pp. 356-360 (Methuen and Co., London, 1967).

[41] Thomas, J. K., Gordon, S., and Hart, E. J., J. Phys. Chem. 68, 1524 (1964).
[42] Kevan, L., J. Amer. Chem. Soc. 87, 1481 (1965).

[43] Anbar, M., Advan. Phys. Org. Chem. 7, 115 (1969).

[44] Kivelson, D., J. Chem. Phys. 45, 1324 (1966).

[45] Solozhenkin, P. M. and Kopitsya, N. I., J. Structur. Chem. 8, 470 (1967).

[46] Bergen, W., and Kossler, H. J., Naturwissenschaften 47, 424 (1960).

[47] Posternak, T., Biochem. Prepn. 2, 57 (1952).

[48] Ref. 6, p. 375 .

[49] Sargeson, A. M., in Ref. [1]. Vol. 6, p. 303.

[50] Jones, M. M., Mechanisms of Inorganic Reactions, Adv. Chem. Ser. 48, 153-162 (1965).

[51] Roy, R. R., and Reed, R. D., Interactions of Photones and Leptones with Matter, pp. 174-224, and 240 (Academic Press, New York, 1968)

[52] J. A. Sartos, Ref. 25, p. 175.

[53] Tl'ykewich, L. A., and Shagisultanova, Khim. Vysok. Energi 3, 207 (1969).

[54] Frieden, E., Osaki, S., and Kobayashi, H., J. Chem. Physiol. 49, 213 (1965).

[55] Lontie, R., and Witters, R., in The Biochemistry of Copper, p. 455, J. Plisach, P. Aisen, and W. E. Blumberry, Eds. (Academic Press, New York, 1966).

[56] Basolo, F., and Pearson, R. G., Mechanisms of Inorganic Reactions, p. 500 (John Wiley \& Sons, New York, 1967).

[57] Vogt, L. H., Jr., Wirt, J. G., and Finkbeiner, H. L., J. Org. Chem. 34, 273 (1969).

[58] Scott, G., Atmospheric Oxidation and Antioxidants, pp. 41, 88, 91, 334, and 341 (Elsevier Publishing Co., New York, 1965).

[59] Kochi, J. K., and Mog, D. M., J. Amer. Chem. Soc. 87, 522 (1965).

[60] Kornblum, N., Michel, R. E., and Kerber, R. C., J. Amer. Chem. Soc. 88, 5662 (1966).

[61] Ref. 6, p. 368.

[62] Chem. Eng. News 48, 30 (1970).

[63] Bayer, E., and Schretzmann, P., in Structures and Bonding, 2, 240, C. K. Torgensen, J. B. Neilands, B. S. Nyholm, D. Reinen, and R. J. P. Williams, Eds. (Springer-Verlag, New York, 1967).

[64] Vaska, L., Science 140,809 (1963).

[65] LaPlace, J., and Ibers, J. A., J. Amer. Chem. Soc. 87, 2581 (1965).

[66] Kashiwagi, T., Yasuoka, N., Kasai, N., Kakudo, M., Takahashi, S., and Hagihara, N., Chem. Commun. 1969, 473.

[67] Simplicio, J., and Wilkins, R. G., J. Amer. Chem. Soc. 91, 1325 (1969).

[68] Calligaris, M., Nardin, G., and Randaccio, L., Chem. Commun. 1969,763 .

[69] Ref. 63, pp. 190-242.

[70] Kertesz, D., Zito, R., and Chiretti, F., in Oxygenases, p. 52, O. Hayaishi, Ed. (Academic Press, London, 1962).

[71] Orgel, L., in T. K. King, H. S. Mason, and M. Morrison (Eds.), Oxidases and Related Redox Systems, p. 110 (John Wiley \& Sons, New York, 1956).

[72] Manwell, C., in Oxygen in Animal Organisms, p. 5, F. Dickens and E. Neil Eds (Pergamon Press, Oxford, 1964).

[73] Gray, R. D., J. Amer. Chem. Soc. 91, 56 (1969).

[74] Wuthrich, K, Helv. Chim. Acta 49, 1400 (1969).

[75] Dannely, R. L., and Farrant, G. C., J. Org. Chem. 34, 2428 (1969).

[76] Nakagawa, K., Konaka, R., and Nakata, T., J. Org. Chem. 27, 1597 (1962).

[77] Konaka, R., Terabe, S., and Kuruma, K., J. Org. Chem. 34, 1335 (1969).

[78] Fieser, L. F., and Fieser, M., Reagents for Organic Synthesis p. 731, (John Wiley, New York, 1967).

[79] George, P., J. Chem. Soc. 1954, 4349.

[80] Stewart, R., Oxidation Mechanisms, p. 159 (W. A. Benjamin, Inc., New York, 1964).

(Paper 74A5-637) 